University of Nebraska - Lincoln

DigitalCommons@University of Nebraska - Lincoln

Publications from USDA-ARS / UNL Faculty

U.S. Department of Agriculture: Agricultural

Research Service, Lincoln, Nebraska

2015

Food reinforcement and delay discounting in zBMI-discordant siblings

Denise M. Feda

James N. Roemmich

April Roberts

Leonard H. Epstein

Follow this and additional works at: https://digitalcommons.unl.edu/usdaarsfacpub

Part of the Agriculture Commons

This Article is brought to you for free and open access by the U.S. Department of Agriculture: Agricultural Research Service, Lincoln, Nebraska at DigitalCommons@University of Nebraska - Lincoln. It has been accepted for inclusion in Publications from USDA-ARS / UNL Faculty by an authorized administrator of DigitalCommons@University of Nebraska - Lincoln. 
Research report

\title{
Food reinforcement and delay discounting in zBMI-discordant siblings ${ }^{\text {मे }}$
}

\author{
Denise M. Feda ${ }^{\mathrm{a}, *}$, James N. Roemmich ${ }^{\mathrm{b}}$, April Roberts ${ }^{\mathrm{a}}$, Leonard H. Epstein ${ }^{\mathrm{a}}$ \\ a Department of Pediatrics, University at Buffalo, Buffalo, NY 14221, United States \\ b USDA-ARS-NPA Grand Forks Human Nutrition Research Center, Grand Forks, ND, United States
}

\section{A R T I C L E I N F O}

\section{Article history:}

Received 30 July 2014

Received in revised form 18 November

2014

Accepted 19 November 2014

Available online 24 November 2014

\section{Keywords:}

Relative reinforcing efficacy

Delay discounting

Sibling

Overweight

\begin{abstract}
A B S T R A C T
Objective: The interaction of food reinforcement and the inability to delay gratification are related to adult energy intake and obesity. This study was designed to test the association of sibling pair differences in relative reinforcing efficacy of food and delay discounting on sibling pair differences in zBMI scores of same-gender zBMI-discordant siblings. Design and methods: We tested main and interactive relationships between delay discounting and relative reinforcing efficacy of food on zBMI discordance in 14 zBMIdiscordant biological sibling pairs (6 female pairs) using a discordant sibling study design. Results: Sibling pair differences in relative reinforcing efficacy of food were associated with sibling pair differences in zBMI $(p=0.046)$; this effect was moderated by delay discounting $(p<0.002)$. Sibling pairs with greater differences in relative reinforcing efficacy and delay discounting had greater differences in zBMI. Conclusions: The combination of greater sibling pair differences in delay discounting and relative reinforcing efficacy is associated with greater discordance in zBMI in adolescent sibling pairs.
\end{abstract}

(c) 2014 Elsevier Ltd. All rights reserved.

\section{Introduction}

For same-gender siblings who are discordant for weight, and who grow up in the same home environment, executive processes that modify daily choices may be one important factor that influences their difference in weight status. For example, one sibling may choose larger delayed rewards such as $\$ 10$ tomorrow whereas the other sibling may always choose smaller immediate rewards such as $\$ 5$ now (a temporal choice known as delay discounting or delay of gratification) (Bickel, Madden, \& Petry, 1998). Greater delay discounting is associated with obesity (Rasmussen, Lawyer, \& Reilly, 2010; Weller, Cook, Avsar, \& Cox, 2008) and future weight gain (Francis \& Susman, 2009; Seeyave et al., 2009) in children and adults. Likewise, one sibling may choose to assign greater value to food compared to their sibling, who may place greater value on non-food alternatives. The reinforcing value of food is measured by how hard someone is willing

Acknowledgements: DF, JNR, LHE conceived of the study design and methods. DF and AR implemented the experiments, DF performed the data analysis, generated the tables and figures, and composed the initial draft of the manuscript. All authors contributed to revisions and had final approval of the submitted and published versions. Appreciation is granted to Molly Walsh for recruitment, data collection, data entry, and protocol implementation. This research was supported by NIH grant R01HD64958 to Dr. Roemmich. The study sponsors had no role in study design, collection, analysis, and interpretation of the data, writing of the report, or decision to submit the manuscript for publication.

* Corresponding author.

E-mail address: denise.feda@waldenu.edu (D.M. Feda). to work for food (Epstein, Leddy, Temple, \& Faith, 2007). Greater reinforcing value of food is associated with obesity (Epstein et al., 2007; Giesen, Havermans, Douven, Tekelenburg, \& Jansen, 2010) and future weight gain (Carr, Lin, Fletcher, \& Epstein, 2014; Hill, Saxton, Webber, Blundell, \& Wardle, 2009) in children and adults. Reinforcing efficacy is also used to measure food reinforcement, specific to choices of purchasing food, and approximates reinforcing values of food obtained from behavioral choice responding paradigms (Epstein, Dearing, \& Roba, 2010).

When combined, an inability to delay gratification (high delay discounting) and high relative reinforcing value of food is known as reinforcement pathology (Carr, Daniel, Lin, \& Epstein, 2011). Adults with traits of high delay discounting and high food reinforcement consume greater energy in an ad libitum eating session (Rollins, Dearing, \& Epstein, 2010) and have greater BMI (Epstein et al., 2014). The effect of the combination of high delay discounting and high relative reinforcing value of food on weight status or eating has not yet been tested in adolescents. The prefrontal cortex region of the brain is immature in adolescents, leading to a biological vulnerability toward immediate reward and sensation seeking (Casey, Getz, \& Galvan, 2008; Potenza, 2013), and thus potentially a greater vulnerability toward high delay discounting. Moreover, given that $18.4 \%$ of all U.S. adolescents aged 12-19 years were obese in 2009-2010 (Ogden, Carroll, Kit, \& Flegal, 2012), there is a clear need to understand factors that may influence how non-overweight and overweight adolescents make choices regarding food and eating.

The current study uses the discordant sibling design as a novel means of testing the ability of delay discounting and high food 
reinforcement to predict differences in sibling adiposity, both as independent factors and in combination. The design reduces the need to adjust for some potential confounders such as socioeconomic status, and parental weight status. This design may also partially account for some genetic factors as siblings share up to $50 \%$ of their genes (Allison, 1996). Comparing two related discordant adolescent siblings is a stronger design than comparing unrelated nonoverweight and overweight adolescents. Another novel aspect of this design is the ability to determine which experiences and behaviors are not shared by the discordant sibling pairs and to test whether those non-shared experiences and behaviors are associated with differences in weight status. In toto, the use of discordant siblings is a powerful approach to study the relationship between delay discounting, food reinforcement, and adiposity, and as such, the association between putative non-shared experiences and behaviors with sibling pair differences in weight status can be tested with relatively small sample sizes (Kenny, Kashy, \& Cook, 2006). Thus, the purpose of this study was to test the association of delay discounting and food reinforcement with weight status using a discordant sibling study design in an adolescent population. We hypothesized that overweight siblings would have greater delay discounting and greater relative reinforcing efficacy of food compared to their non-overweight sibling, and that the differences in delay discounting and relative reinforcing efficacy between the siblings would be positively associated with their differences in adiposity.

\section{Methods and procedures}

\section{Participants}

Twenty-three same gender sibling pairs (female pairs =14) participated in the follow-up study during the time period of December 2012 through August 2013. Siblings were originally recruited approximately one year prior to the follow-up based on their age and weight status. For the original study, both siblings had to be between 13 and 17 years, one sibling must have been at or above the 85th BMI percentile, and the other sibling needed to be below the 70th BMI percentile. Siblings must have also had the same biological parents and must have self-assessed themselves as a stage II or greater for genital (boys)/breast (girls) development (Duke, Litt, \& Gross, 1980) to be included in the original study. Families from the original study were screened via a brief phone interview and were excluded if: either of the siblings had medical disorders or psychiatric disorders that affected their weight, eating or appetite; if they were taking any medications that would affect their weight, eating or appetite; if they had limitations to physical activity, pregnancy, or any developmental delay; or if they used tobacco or nicotine. There were no BMI restrictions for the follow up study; all other exclusion criteria remained the same. Fourteen sibling pairs (6 female pairs) remained discordant at the time of follow-up and were included in the analysis for this study. Seven of the discordant sibling pairs had older siblings that were overweight; seven discordant pairs had younger overweight siblings. Parents and adolescents signed written informed consent and assent, and the study was approved by the Social and Behavioral Sciences Institutional Review Board.

\section{Design and procedures}

Sibling pairs eligible for the study were scheduled for 3 weekly laboratory visits and one week of activity monitoring. All laboratory tests were conducted in experimental rooms equipped with negative air pressure, sound insulating drywall, and HEPA air filtration. Only study visits pertinent to the current study analyses are described. Before each laboratory visit, siblings confirmed that they were feeling well, they had not eaten in the last 3 hours, and they did not consume any of the study foods (powdered sugar donuts, chocolate chip cookies, nacho cheese flavored chips, chocolate candies) the day before or day of their visit. The order of visits was counterbalanced between sibling pairs. Siblings were separated into separate rooms for every visit. During one visit, siblings filled-out a series of surveys, including the relative reinforcing efficacy questionnaire, and also had their height and weight measured. Parents completed a demographic questionnaire. On another visit, siblings completed a delay discounting task. Participants were debriefed and compensated with a $\$ 100$ check or gift card to a store of their choice. Parents received compensation for travel.

\section{Measurement}

\section{Anthropometrics}

Weight was measured to the nearest $0.01 \mathrm{~kg}$ using a calibrated scale (Tanita, Arlington Heights, IL). Height was measured to the nearest $0.01 \mathrm{~cm}$ using a calibrated stadiometer (SECA, Hamburg, Germany). BMI z-scores were calculated using CDC published guidelines (Kuczmarski et al., 2000).

\section{Pubertal development}

To self-assess their Tanner stage of development, adolescents were given standardized drawings with appropriate text depicting 5 stages of breast development for girls and 5 stages of genital development for boys. While in a private room, each adolescent was asked to circle the picture that best indicated their own development. Previous studies have shown correlations between self-assessment and physician ratings (Duke et al., 1980).

\section{Demographics}

Socioeconomic status and demographics were assessed using a standardized questionnaire filled out by the parents. Data were collected on age, race, ethnicity, household income, educational attainment, employment, and marital status.

\section{Relative reinforcing efficacy}

To complete the questionnaire task, participants first ranked their liking of four different foods: powdered sugar donuts, chocolate chip cookies, nacho cheese flavored chips, chocolate candies. A $100 \mathrm{kcal}$ portion photo of their top-ranked food was placed in front of the participant while they completed the questionnaire. Participants indicated how many portions of the snack food they would consume on a typical day (without saving portions for future days) for the following price points: 0 (free), $\$ 0.01, \$ 0.05, \$ 0.13, \$ 0.25, \$ 0.50, \$ 1$, $\$ 2, \$ 3, \$ 4, \$ 5, \$ 6, \$ 11, \$ 35, \$ 70, \$ 140, \$ 280, \$ 560, \$ 1120$. Prices were always presented in ascending order.

Measuring reinforcing efficacy as a substitute for reinforcing value or food reinforcement saves time and laboratory resources while generating similar data and demand curves that describe behavioral choices associated with food. Instead of measuring responding for a food, the questionnaire task asks participants about purchasing a food at different amounts, with the main goal of creating a demand curve. Relative reinforcing efficacy measured using a questionnaire is correlated with traditional laboratory measures of relative reinforcing value of food (Epstein et al., 2010).

\section{Delay discounting task}

The delay discounting task measured the amount at which participants discounted a $\$ 10$ and $\$ 100$ reward with increasing time delay (Odum, Baumann, \& Rimington, 2006). Two cards with 
different dollar amounts were placed in front of the participant; the time delayed card was on the right ("Would you like \$10 in 1 day?"), and the immediate value card was on the left ("Would you like \$10 now?"). Six time delays included: 1 day, 2 days, 1 week, 2 weeks, 1 month, and 6 months. The values for the immediate outcome changed after each trial beginning at $\$ 10$ and then decreasing to $\$ 9.90, \$ 9.75, \$ 9.50, \$ 9.25, \$ 9.00, \$ 8.50, \$ 8.00, \$ 7.50, \$ 7.00, \$ 6.50$, $\$ 6.00, \$ 5.50, \$ 5.00, \$ 4.50, \$ 4.00, \$ 3.50, \$ 3.00, \$ 2.50, \$ 2.00, \$ 1.50$, $\$ 1.00, \$ 0.75, \$ 0.50, \$ 0.25$ and $\$ 0.10$. The immediate values for the $\$ 100$ trial are the preceding values multiplied by 10 . Participants indicated their desired reward (either immediate or delayed) by pointing to the appropriate card. The order (ascending or descending) of the immediate value rewards and starting dollar reward ( $\$ 10$ or \$100) were counterbalanced between sibling pairs. Siblings had the same order. Only data from the $\$ 10$ reward were used in the analysis because smaller rewards are more sensitive and the ability to delay gratification increases as the delayed amount increases (Baker, Johnson, \& Bickel, 2003; Green, Myerson, \& McFadden, 1997). The rewards were hypothetical.

\section{Analytic plan}

\section{Preliminary analyses}

To describe participants' food reinforcement the dependent measure, breakpoint, was calculated as the first dollar amount at which participants chose to consume zero portions of snack food. Breakpoint is reported in US dollars. To describe participants' discounting of money, indifference points were calculated based on two switch points for each delay trial. The two switch points included the immediate reward when the participant switched from the delayed reward to the immediate reward, and the immediate reward when the participant switched from the immediate reward to the delayed reward. Taking an average of these switch points resulted in one indifference point for each time delay. The indifference points were used in the data analysis to calculate the area under the curve (AUC) (Myerson, Green, \& Warusawitharana, 2001). The AUC equation $\mathrm{x}_{2}-\mathrm{x}_{1}\left[\left(\mathrm{y}_{1}+\mathrm{y}_{2}\right) / 2\right]$ was summed for each delay period, where $\mathrm{x}_{1}$ and $\mathrm{x}_{2}$ are successive delays and $\mathrm{y}_{1}$ and $\mathrm{y}_{2}$ are the corresponding immediate values (Myerson et al., 2001). AUC ranged from 0 (highest discounting) to 1 (no discounting). To describe differences between sibling pairs for physical characteristics, food reinforcement and delay discounting, the non-overweight sibling's values were subtracted from the overweight sibling's values. Paired t-tests were used to compare non-overweight and overweight siblings' physical characteristics, relative reinforcing efficacy breakpoint values and delay discounting. To test for co-linearity, pairwise correlations of sibling pair differences in delay discounting and sibling pair differences in food reinforcement were run. Statistical significance was set at $p=0.025$ for these comparisons. Intraclass correlations with 95\% CIs (ICC, $\rho$ ) (McGraw \& Wong, 1996) were performed to measure sibling resemblance. An ICC of 0.00.1 indicates no similarity; $0.11-0.4$ slight similarity; $0.41-0.6$ fair similarity; 0.61-0.8 moderate similarity; and 0.81-1.0 substantial similarity (Shrout, 1998). Hypothesis testing: General linear models were used to test the associations between sibling pair zBMI differences and sibling pair differences in food reinforcement and delay discounting as main effects, and with the interaction of sibling pair differences in food reinforcement and sibling pair differences in delay discounting. Sibling pair difference in age was used as a covariate in all models (Kral et al., 2012; Roemmich, White, Paluch, \& Epstein, 2010). Gender was considered as a covariate and was not a significant predictor $(p=0.33)$ and was not included in the final models. The effects of ethnicity were considered by running the same general linear models using only white, non-Hispanic sibling pairs. The models remained unchanged so all eligible sibling pairs were kept in the analysis. Distribution plots of residuals were used to confirm that model assumptions of normality were not violated. Data analysis was completed using SYSTAT 13.00.05 and SPSS 17.0.

\section{Results}

The 14 discordant sibling pairs' racial demographics included 13 white sibling pairs and 1 African American sibling pair. For ethnicity, one sibling pair was Hispanic and 13 sibling pairs were nonHispanic. The average age at follow-up of the non-overweight siblings was 17.6 years (SE: 0.37 ; SD: 1.4 ); overweight siblings were on average 16.6 years old (SE: 0.45 ; SD: 1.7 ), with no significant difference between overweight and non-overweight $(p=0.11)$. At follow-up mean BMI percentile for overweight siblings was 93.1 percentile (SE: 0.83, SD 3.1), and 46.8 percentile (SE 4.6, SD 17.2) for non-overweight siblings. Siblings were different by BMI percentile $(p<0.001)$. The income category mode for families was $\$ 30,000-$ $\$ 49,999$, and highest level of education attained by parents was completion of a college degree.

Table 1 shows the mean relative reinforcing efficacy breakpoints (the amount of money at which the participant would purchase no portions of the food) and delay discounting AUC for non-overweight and overweight siblings. Sibling pair differences in delay discounting and relative reinforcing efficacy were not correlated $(\mathrm{r}=0.0027, p=1.0)$.

As a group, overweight siblings were willing to pay at most about $\$ 8$ per portion of 100 -calorie snack food. Non-overweight siblings were willing to pay at most about $\$ 5$ per portion of 100 -calorie snack food. Paired t-tests revealed no differences between non-overweight and overweight/obese siblings' relative reinforcing efficacy breakpoint $(p=0.17)$, or discounting of money $(p=0.38)$. ICC (Table 1 ) indicated little to no sibling resemblance in delay discounting $(p=0.53)$ or food reinforcement $(p=0.13)$.

After adjusting for sibling pair differences in age, linear regression models showed no association between sibling pair differences in delay discounting and sibling pair differences in zBMI $(B=-0.04$, $95 \% \mathrm{CI}=(-1.64,0.74), p=0.44)$. After adjusting for sibling pair differences in age, linear regression models showed a positive association between sibling pair differences in relative reinforcing efficacy and sibling pair differences in zBMI $(B=0.02,95 \%$ $\mathrm{CI}=(0.0005,0.06), p=0.046)$. Regression coefficients and $\mathrm{R}^{2}$ are provided in Table 2 for the interaction model examining the association of sibling pair differences in relative reinforcing efficacy of snack foods $\times$ sibling differences in delay discounting on sibling pair differences in zBMI. After adjustment for the difference in sibling age, the interaction model explained $49 \%$ of the variance and the interaction term was associated with sibling pair difference in zBMI.

Table 1

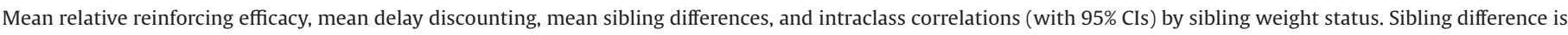
calculated by subtracting the raw data of the non-overweight sibling from the overweight sibling.

\begin{tabular}{|c|c|c|c|c|}
\hline & Non-overweight sibling & Overweight sibling & Sibling difference & ICC \\
\hline Relative reinforcing efficacy (breakpoint, \$USD) & $5.3 \pm 1.1$ & $8.3 \pm 2.3$ & $3.0 \pm 1.4$ & $0.29(-0.24,0.69)$ \\
\hline Delay discounting (AUC) & $0.15 \pm 0.02$ & $0.13 \pm 0.02$ & $0.01 \pm 0.03$ & $-0.02(-0.52,0.49)$ \\
\hline
\end{tabular}

Data are mean \pm SE.

AUC - area under the curve. 
Table 2

Regression coefficients, standard error, standardized regression coefficients (ß), 95\% confidence intervals, and $p$-values for variables in the linear regression model testing the association of sibling pair differences in zBMI with: sibling pair differences in age, sibling pair differences in relative reinforcing value, sibling pair differences in delay discounting and the interaction between sibling pair differences in relative reinforcing efficacy $\times$ sibling pair differences in delay discounting. $R_{R E}$ is sibling difference in relative reinforcing efficacy of snack foods; $\mathrm{DD}_{\mathrm{D}}$ is sibling difference in delay discounting.

\begin{tabular}{lrlrll}
\hline Variable & Coefficient & $\begin{array}{l}\text { Standard } \\
\text { Error }\end{array}$ & $\beta$ & $\mathrm{CI}$ & $p$ \\
\hline Intercept & 1.49 & 0.10 & & $(1.28,1.68)$ & 0.000 \\
Age difference & -0.12 & 0.04 & -0.52 & $(-0.19,-0.04)$ & 0.006 \\
RRE $_{\mathrm{D}}$ & 0.04 & 0.01 & 0.60 & $(0.02,0.06)$ & 0.003 \\
$\mathrm{DD}_{\mathrm{D}}$ & -2.10 & 0.63 & -0.71 & $(-3.41,-0.79)$ & 0.003 \\
$\mathrm{RRE}_{\mathrm{D}} \times \mathrm{DD}_{\mathrm{D}}$ & 0.43 & 0.12 & 0.76 & $(0.18,0.68)$ & 0.002 \\
& & & & $\mathrm{R}=0.70$ & \\
& & & & $\mathrm{R}^{2}=0.49$ & \\
\hline
\end{tabular}

Figure 1 shows the interaction between sibling relative reinforcing efficacy difference and sibling delay discounting difference. To illustrate the interaction, regression models were run using the mean value \pm 1 SD for both sibling pair differences in delay discounting and sibling pair differences in reinforcing efficacy variables. The figure shows how sibling pair differences in delay discounting and sibling pair differences in reinforcing efficacy interact to affect sibling pair differences in zBMI. Sibling pairs with large differences in delay discounting and large differences in reinforcing efficacy have the greatest differences in zBMI (solid line).

Using simple slopes analysis and the regression equation in Table 2, sibling pair differences in relative reinforcing efficacy of food was associated with that of differences in sibling zBMI when delay discounting difference is large $(\beta=3.31, p<0.001)$, and to a lesser extent when the delay discounting difference is small $(\beta=0.35$, $p<0.001)$. As shown in Fig. 1, siblings with greater differences in relative reinforcing efficacy and with greater differences in delay discounting had greater differences in zBMI.

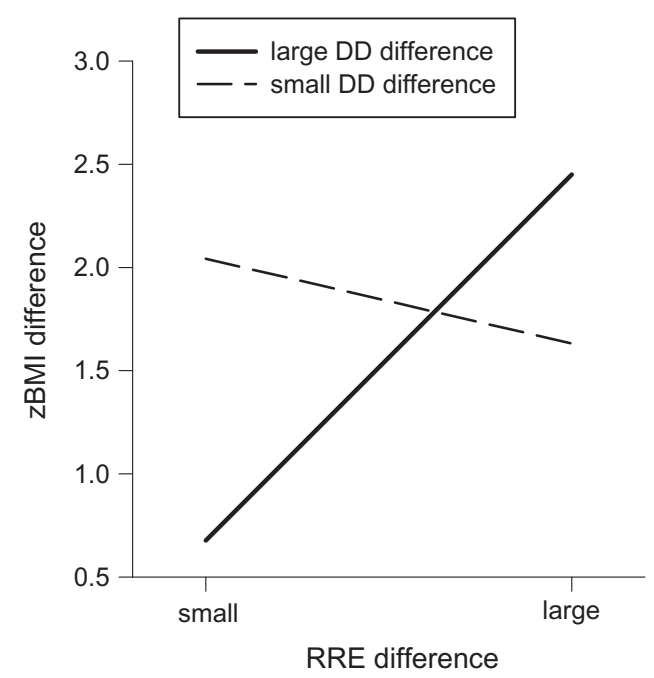

Fig. 1. The association of sibling differences in zBMI and the interaction of sibling differences in relative reinforcing efficacy $\times$ sibling differences in delay discounting. Linear regression analyses revealed that the interaction of sibling differences in relative reinforcing efficacy $\times$ sibling differences in delay discounting $(p=0.002)$. Large and small difference values in delay discounting and relative reinforcing efficacy were computed using the mean $\pm 1 \mathrm{SD}, \mathrm{N}=14$ sibling pairs, or 28 individuals.

\section{Discussion}

We have shown for the first time that differences in zBMIdiscordant adolescent siblings' relative reinforcing efficacy of food and delay discounting are associated with differences in their zBMI. Reinforcing efficacy of food, measured via questionnaire, is correlated with maximal responses for food (food reinforcement) in the laboratory (Epstein et al., 2010). Our results suggest that having high food reinforcement and inability to delay gratification, also known as reinforcement pathology (Carr et al., 2011), may be a primary behavioral processes contributing to the siblings' discordance in weight. This is also the first study to show that the combination of high food reinforcement and the inability to delay gratification is associated with weight status in an adolescent sample.

Our results suggest that sibling differences in zBMI are 0.43 units higher when the overweight sibling has a 1 SD larger relative reinforcing efficacy of food compared to the non-overweight sibling. There were no differences in zBMI when the overweight sibling had a 1 SD larger delay discounting, compared to the non-overweight sibling. The greatest effects of zBMI were found when differences in relative reinforcing efficacy were moderated by differences in delay discounting: zBMI difference scores were 1.7 units higher for the overweight siblings with 1 SD larger relative reinforcing efficacy of food and 1 SD larger differences in delay discounting vs. 1 SD smaller relative reinforcing efficacy of food and 1 SD larger differences in delay discounting compared to the non-overweight sibling. Additionally, based on ICCs, siblings discordant for zBMI had virtually no resemblance in food reinforcement and poor resemblance in delay discounting, indicating there is a substantial amount of nonshared behavioral choice among sibling pairs discordant for adiposity. Non-shared behaviors and environments may partially explain the difference is siblings' adiposity. The discordance in behavioral measures of choice, such as a greater relative reinforcing efficacy of food, especially when combined with high delay discounting (reinforcement pathology), appears to be associated with sibling weight discordance.

This study has several potential limitations. First, the study uses a small sample size, which may heighten the risk of type I error. However, given the discordant sibling design, with our sample of 14 sibling pairs we had $80 \%$ power to reliably detect pair nonindependence at an ICC of approximately 0.7 at an $\alpha$ of 0.05 and an ICC of approximately 0.6 at an $\alpha$ of 0.01 (Kenny et al., 2006). In effect, we could reliably detect down to a 'moderate' similarity within siblings. Second, another potential limitation is our use of the relative reinforcing efficacy questionnaire as a measure of relative reinforcing value instead of using an experimental laboratory task. Although the questionnaire has been validated against the relative reinforcing value task (Epstein et al., 2010), using the laboratory task may have yielded additional measures of behavioral differences between siblings (e.g., length of time to work for each portion of food). Additionally, the participants in our study may have found food more reinforcing than their peers, or they may not have understood the task. This may explain why adolescents in the study were willing to pay at most $\$ 5-\$ 8$ for their snack portions. Third, adolescents' self-perception of their weight status may have influenced their choice of behaviors while in the laboratory setting, either toward choosing to purchase more or less snack foods during the relative reinforcing efficacy task. There may also have been unmeasured confounding variables that contribute to the difference in the measures of delay discounting or relative reinforcing efficacy that may better explain the difference in sibling adiposity discordance. Fourth, we did not collect genetic material from the participants in our study and we assume that the siblings share roughly $50 \%$ of their genetics, and differ on the other 50\%. The siblings could have differed in their genetics, pertinent to genes that may influence brain function and subsequent behavior such as the DRD2 genotype 
(Epstein et al., 2007). Finally, our paper focused solely on behavioral choices that may influence food intake and did not consider complimentary or competing hypotheses involving variables such as physical activity (Westerterp, 2010), sleep deprivation (Hart et al., 2013), or other physiological or environmental conditions that may influence weight directly or may influence behavioral choice.

In summary, the current study showed how adolescent sibling pair differences in relative reinforcing efficacy of food and delay discounting are associated with sibling pair differences in zBMI. Sibling pair differences in delay discounting moderated the effect of sibling pair differences in relative reinforcing efficacy of food on differences in zBMI. These results provide additional support for the role of combined high food reinforcement and inability to delay gratification (reinforcement pathology) in obesity.

\section{References}

Allison, D. B. (1996). The use of discordant sibling pairs for finding genetic loci linked to obesity. Practical considerations. International Journal of Obesity, 20, 553-560.

Baker, F., Johnson, M. W., \& Bickel, W. K. (2003). Delay discounting in current and never-before cigarette smokers. Similarities and differences across commodity, sign, and magnitude. Journal of Abnormal Psychology, 112, 382-392.

Bickel, W. K., Madden, G. J., \& Petry, N. M. (1998). The price of change. The behavioral economics of drug dependence. Behavior Therapy, 29, 545-565.

Carr, K. A., Daniel, T. O., Lin, H., \& Epstein, L. H. (2011). Reinforcement pathology and obesity. Current Drug Abuse Reviews, 4, 190-196.

Carr, K. A., Lin, H., Fletcher, K. D., \& Epstein, L. H. (2014). Food reinforcement, dietary disinhibition and weight gain in nonobese adults. Obesity, 22, 254-259.

Casey, B. J., Getz, S., \& Galvan, A. (2008). The adolescent brain. Developmental Review, $28,62-77$.

Duke, P. M., Litt, I. F., \& Gross, R. T. (1980). Adolescents self-assessment of sexualmaturation. Pediatrics, 66, 918-920.

Epstein, L. H., Dearing, K. K., \& Roba, L. G. (2010). A questionnaire approach to measuring the relative reinforcing efficacy of snack foods. Eating Behaviors, 11, 67-73.

Epstein, L. H., Leddy, J. J., Temple, J. L., \& Faith, M. S. (2007). Food reinforcement and eating. A multilevel analysis. Psychological Bulletin, 133, 884-906.

Epstein, L. H., Temple, J. L., Neaderhiser, B. J., Salis, R. J., Erbe, R. W., \& Leddy, J. J. (2007). Food reinforcement, the dopamine D2 receptor genotype, and energy intake in obese and nonobese humans. Behavioral Neuroscience, 121, 877-886.

Epstein, L., Jankowiak, N., Fletcher, K., Carr, K., Nederkoorn, C., Raynor, H., et al. (2014). Women who are motivated to eat and discount the future are more obese. Obesity, 22, 1394-1399.

Francis, L. A., \& Susman, E. J. (2009). Self-regulation and rapid weight gain in children from age 3 to 12 years. Archives of Pediatrics $\mathcal{E}$ Adolescent Medicine, 163, 297-302.
Giesen, J. C. A. H., Havermans, R. C., Douven, A., Tekelenburg, M., \& Jansen, A. (2010) Will work for snack food. The association of BMI and snack reinforcement. Obesity, 18, 966-970.

Green, L., Myerson, J., \& McFadden, E. (1997). Rate of temporal discounting decreases with amount of reward. Memory E' Cognition, 25, 715-723.

Hart, C. N., Carskadon, M. A., Considine, R. V., Fava, J. L., Lawton, J., Raynor, H. A., et al. (2013). Changes in children's sleep duration on food intake, weight, and leptin. Pediatrics, 132, e1473-e1480.

Hill, C., Saxton, J., Webber, L., Blundell, J., \& Wardle, J. (2009). The relative reinforcing value of food predicts weight gain in a longitudinal study of $7-10-y$-old children. The American Journal of Clinical Nutrition, 90, 276-281.

Kenny, D. A., Kashy, D. A., \& Cook, W. L. (2006). Dyadic data analysis. New York: Guilford Press.

Kral, T. V. E., Allison, D. B., Birch, L. L., Stallings, V. A., Moore, R. H., \& Faith, M. S. (2012). Caloric compensation and eating in the absence of hunger in 5-to 12 -y-old weight-discordant siblings. The American Journal of Clinical Nutrition, 96, 574-583.

Kuczmarski, R. J., Ogden, C. L., Grummer-Strawn, L. M., Flegal, K. M., Guo, S. S., Wei, R., et al. (2000). CDC growth charts for the United States. Methods and development. (Vol. Series Report 11, No. 246). Hyattsville, MD: National Center for Health Statistics.

McGraw, K. O., \& Wong, S. P. (1996). Forming inferences about some intraclass correlation coefficients. Psychological Methods, 1, 30-46.

Myerson, J., Green, L., \& Warusawitharana, M. (2001). Area under the curve as a measure of discounting. Journal of the Experimental Analysis of Behavior, 76, 235-243.

Odum, A. L., Baumann, A. A. L., \& Rimington, D. D. (2006). Discounting of delayed hypothetical money and food. Effects of amount. Behavioural Processes, 73, 278-284.

Ogden, C. L., Carroll, M. D., Kit, B. K., \& Flegal, K. M. (2012). Prevalence of obesity in the United States, 2009-2010. In NCHS data brief (Vol. 82, pp. 1-8). Hyattsville, MD: National Center for Health Statistics.

Potenza, M. N. (2013). Biological contributions to addictions in adolescents and adults. Prevention, treatment, and policy implications. The Journal of Adolescent Health: Official Publication of the Society for Adolescent Medicine, 52, S22-S32.

Rasmussen, E. B., Lawyer, S. R., \& Reilly, W. (2010). Percent body fat is related to delay and probability discounting for food in humans. Behavioural Processes, 83, 23-30.

Roemmich, J. N., White, T. M., Paluch, R., \& Epstein, L. H. (2010). Energy intake, parental control of children's eating, and physical activity in siblings discordant for adiposity. Appetite, 55, 325-331.

Rollins, B. Y., Dearing, K. K., \& Epstein, L. H. (2010). Delay discounting moderates the effect of food reinforcement on energy intake among non-obese women. Appetite, $55,420-425$.

Seeyave, D. M., Coleman, S., Appugliese, D., Corwyn, R. F., Bradley, R. H., Davidson, N. S., et al. (2009). Ability to delay gratification at age 4 years and risk of overweight at age 11 years. Archives of Pediatrics \& Adolescent Medicine, 163, 303-308.

Shrout, P. E. (1998). Measurement reliability and agreement in psychiatry. Statistical Methods in Medical Research, 7, 301-317.

Weller, R. E., Cook, E. W., Avsar, K. B., \& Cox, J. E. (2008). Obese women show greater delay discounting than healthy-weight women. Appetite, 51, 563-569.

Westerterp, K. R. (2010). Physical activity, food intake, and body weight regulation. Insights from doubly labeled water studies. Nutrition Reviews, 68, 148-154. 